\title{
RADIOXENONS: THEIR ROLE IN MONITORING A COMPREHENSIVE TEST BAN TREATY
}

Richard W. Perkins, PNNL

Leslie A. Casey, US DOE/NN-20

June 1996

Prepared by the Pacific Northwest National Laboratory Richland WA 99352

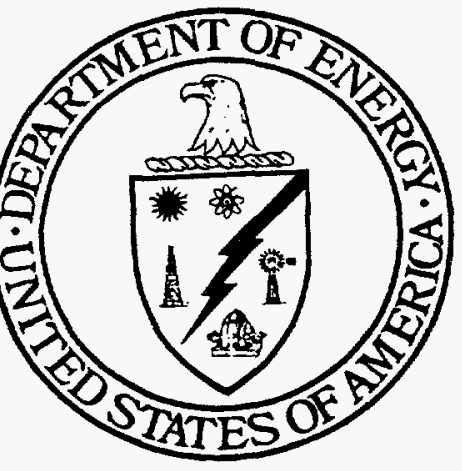

United States

Department of Energy

P.O. Box 550

Richland WA 99352

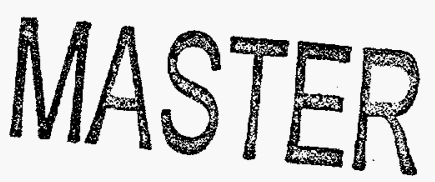

DISTRBUTION OF THS DOCUMENT IS UNLMTTER 


\title{
Radioxenons: Their Role in Monitoring a Comprehensive Test Ban Treaty
}

\author{
U.S. efforts to achieve a verifiable Comprehensive nuclear Test Ban Treaty (CTBT) \\ include enhancing detection technologies. Automation for the extremely sensitive \\ measurement of the radioxenon fission products provides an important verification tool.
}

\author{
By Richard W. Perkins and Leslie A. Casey
}

Monitoring for xenon radionuclides which are produced in a nuclear detonation can provide a strong deterrent to the violation of a Comprehensive nuclear Test Ban Treaty (CTBT). There are 18 known radioactive xenon isotopes produced in nuclear fission with half-lives ranging from less than one second to 11.9 days. However, only four of these remain in significant amounts more than a day after a detonation. The nonreactive noble gas properties of the xenon radionuclides ensure that they will be the first and perhaps the only fission products released in a covert nuclear weapons test. However, in order for radioxenon monitoring to be practical, it was necessary to develop an automated measurement system which could operate unattended for periods of months, measure the entire spectrum of radioxenons, and provide hundreds of times better sensitivities than current laboratory procedures. This capability was developed at the U.S. Department of Energy's Pacific Northwest National Laboratory based on rapid separation of atmospheric xenon coupled with a unique high sensitivity measurement device for the radioxenons. A fieldable prototype analyzer is scheduled for testing in August 1996 with commercial availability planned by 1998 .

During the past three years, the United States has vigorously pursued negotiations at the Geneva Conference on Disarmament (CD) to establish a verifiable Comprehensive Test Ban Treaty which would prohibit even the smallest nuclear explosion.

Radionuclide monitoring is of particular importance since it is the only method which can provide absolute assurance that a nuclear detonation has occurred. Radionuclide monitoring literally involves the collection and analysis of a part of the bomb. Other monitoring methods can provide evidence of a suspect event but cannot show that the event was nuclear. Initial tests of nuclear weapons by the U.S., U.S.S.R., United Kingdom, France, and the Peoples Republic of China were conducted in the atmosphere, and particulate fission product debris from such tests was readily observable over the entire hemisphere in which they were conducted. However, with the development and application of underground testing technologies, the release of particulate fission products could be largely or completely eliminated and only the nonreactive gaseous fission products which are produced directly in the detonation may be vented to the atmosphere. Therefore, the only opportunity to detect or confirm a suspect event may be through observation of the unique ratios of the radioxenon fission products. Of these, ${ }^{135} \mathrm{Xe}(9.10 \mathrm{hr}),{ }^{133 m \mathrm{Xe}}(2.19 \mathrm{day})$, and ${ }^{133 \mathrm{X}} \mathrm{Xe}(5.24$ day) are the most abundant after a vent. The longer-lived radionuclide ${ }^{13 i m} X e$ ( 11.9 day) is also produced but its concentration is orders of magnitude lower than any of the others. However, ${ }^{131 \mathrm{~m}} \mathrm{Xe}$ can enter the atmosphere from early reprocessing of nuclear fuels or from medical isotope production and usage. Therefore, its measurement is important in differentiating between a nuclear test and the other sources of radioxenon (i.e., reactor operations, fuel reprocessing, medical isotope production and usage).

For verification of a CTBT, an International Monitoring System (IMS) is proposed which may include a world-wide network of stations where airborne radionuclides, both particulates and radioxenon, are monitored continuously. To be practical, a radioxenon monitoring system must operate automatically, require only annual maintenance and consume only electric power, collect and measure the four radioxenons two or more times a day, provide 100 - to 1000 -fold greater sensitivity than existing laboratory-based technology, differentiate between weapons test radioxenon and those from the previously mentioned sources, and automatically transmit analytical data to the National Data Center (NDC) for relay to the International Data Center (IDC).

High detection sensitivity requirements are necessary since venting from a nuclear detonation may only include a very small fraction of the total radioxenon produced. Subsequent atmospheric dispersion processes can result in major dilution before reaching a monitoring site. High sensitivity measurements of the four xenon radionuclides must be made in order to differentiate between atmospheric radioxenons from nuclear power reactor operations, nuclear fuel reprocessing, or medical isotope production and usage. Consecutive measurements two or more times each day are important since a plume from an underground detonation may pass by a monitoring station in just a few hours. A very important radioxenon is the $9.1 \mathrm{hr}{ }^{135} \mathrm{Xe}$ which is more abundant than any of the other radioxenons during the first few days after a detonation, and its ambient background is negligible. However, its short half-life requires analysis soon after collection in order to minimize the loss of sample through decay.

During the past three years, research has been carried out to develop a radioxenon monitoring system which would meet these requirements. Such a system has been developed and demonstrated and once commercialized, may serve as a monitoring instrument for verification of a CTBT. The technology involves collection of the 


\section{DISCLAIMER}

Portions of this document may be illegible in electronic image products. Images are produced from the best available original document. 



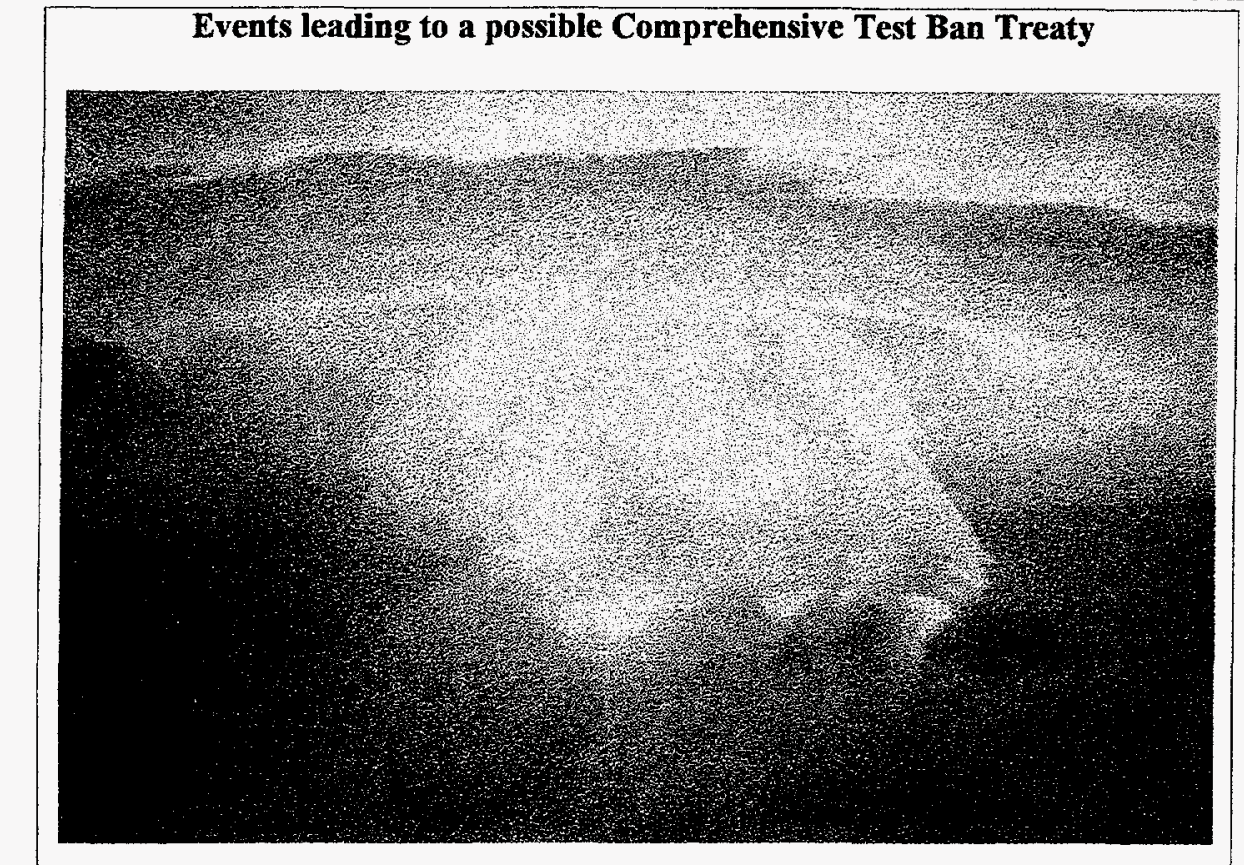

Detonation of the first true thermonuclear device, with a 10.2-megaton yield, occurred on Elugelab Island, Enewetak Atoll on November 1, 1952. Fallout from the second and largest U.S. thermonuclear detonation, which occurred on Bikini Atoll with a yield of 15 megatons, produced serious radiation exposure to the crew of the Japanese fishing vessel, Lucky Dragon, and of residents on nearby atolls, adding further urgency for outlawing nuclear weapons development and testing (see above photo). Because of such health effects, the initial ban focused on ending atmospheric testing. (Photo courtesy of Los Alamos National Laboratory.)

The first detonation of a nuclear weapon occurred on July 16, 1945, at Trinity Test Site at Alamogordo, New Mexico. This $20-\mathrm{kT}$, plutonium-fueled detonation was followed by nuclear explosions over two Japanese cities. A $12.5-\mathrm{kT}^{235} \mathrm{U}$ device was detonated over Hiroshima on August 6, 1945 and a $20-\mathrm{kT}$ plutonium device was detonated over Nagasaki on August 9, 1945, which brought about the end of World War II on August $15,1945$. The enormous loss of life and property damage caused by nuclear explosions were vividly evident at these cities and have ever since provided an impetus for the establishment of treaties banning development, testing, acquisition, and usage of nuclear weapons.

Detonation of the more powerful hydrogen bombs by the U.S. in 1952, the Soviet Union the following year, and of a 15-MT thermonuclear device by the U.S. at Bikini Atoll in March 1954 caused an even more urgent concem to outlaw nuclear weapons development and testing. This latter test resulted in the accidental contamination and radiation sickness of the crew of the Japanese fishing vessel, the Lucky Dragon, and of residents on nearby atolls. Periodic atmospheric testing by the U.S. and the Soviet Union included several multimegaton detonations in 1961 and 1962 . However, this atmospheric testing was formally ended with the signing of the Limited Test Ban Treaty (LTBT) in Moscow on August 5, 1963, by the U.S., the U.S.S.R., and the United Kingdom and its entry into force October 10 of the same year. The LTBT prohibited testing in the atmosphere, in outer space, and underwater, and also underground testing that would allow nuclear debris to be transported beyond the borders of the country conducting the test. This treaty, however, was not accepted by France and the Peoples Republic of China which initiated their atmospheric testing programs in 1960 and 1964 , respectively. Further progress toward cessation of nuclear weapons development and testing was achieved with the Treaty on Nonproliferation of Nuclear Weapons (NPT) which was originally signed by 62 nations and entered into force on March 5, 1970. This treaty prohibited acquisition of nuclear weapons by non-weapons states and included safeguards provisions to monitor for processes leading to weapons production.

Additional progress in limiting underground testing was achieved with the signing of the Threshold Test Ban Treaty (TTBT) on July 3, 1974, which prohibited tests having a yield of greater than $150 \mathrm{kT}$. Nevertheless, atmospheric testing of multimegaton weapons by the Peoples Republic of China, which was not a signatory, continued through 1980 .

During the past three years, a rapid succession of events has taken place toward a verifiable Comprehensive Test Ban Treaty (CTBT). In April 1993, President Clinton, at the Vancouver summit conference with President Yeltsin, committed the Administration to the negotiation of a muitilateral nuclear test ban. In December 1993, the United Nations General Assembly approved by consensus a resolution to ban all nuclear weapons tests, and in January 1994 the Conference on Disarmament (CD) began negotiations on a CTBT. The 1994 negotiations are centered on a rolling text which is to be the basis for the final treaty. There is general agreement that a treaty verification regime would include four monitoring techniques-seismic, radionuclide, hydroacoustic and infrasound.

A major change in treaty emphasis resulted from an announcement on August 11, 1995, by President Clinton that the United States would seek a zero-yield test ban which would ban tests of any size, by any signatory anywhere on earth. This announcement was welcomed by most nations in the CD and energized the negotiation process. The zero-yield provision did, however, place a serious burden on the monitoring requirements, and $R \& D$ to enhance detection sensitivity by all monitoring technologies is a continuing process. atmospheric xenon by passing filtered, dry, cold air through a large charcoal adsorption bed for a specified period of time, followed by xenon elution and readsorption on a smaller adsorption bed prior to its injection into a specialized gas cell scintillation counter where high sensitivity energy analysis and electronphoton coincidence counting of the four xenon radionuclides are performed. This unique approach allows consecutive measurements of atmospheric radioxenon with sensitivities which are far greater than any method which has heretofore been used.

\section{IMPORTANCE OF MONITORING FOR COMPLIANCE}

The intent of a Comprehensive Test Ban Treaty is to stop all nuclear explosions by all countries and thereby discourage weapons development. Support for a Comprehensive Test Ban Treaty is dependent on countries being confident that a potential aggressor will not develop or test nuclear weapons. Treaty compliance is much more certain where reliable monitoring systems are in operation. A determined evader would seek to test in a manner which minimizes all observable indications of the test.

Essentially all of the evasion scenarios which conceivably reduce detectability by other monitoring methods (seismic, hydroacoustic or infrasound) still have a substantial probability for, or in fact will result in venting of xenon noble gas radionuclides to the atmosphere. A worldwide monitoring system for continuous measurement of radioxenons should, therefore, provide a means for detection, and thus serve as a deterrent to conducting nuclear explosions.

\section{AIRBORNE DEBRIS FROM PAST NUCLEAR TESTS}

When atmospheric testing was conducted, it was very easy to confirm the detonation based on collection and analysis of particulate airborne radioactive debris. With the Limited Test Ban Treaty (LTBT) signed in 1963 in Moscow, which prohibited atmospheric testing of nuclear weapons by the signatories, more extensive underground tests were initiated. However, many of these underground tests vented in a very major way, resulting in a substantial release of the gases and a 


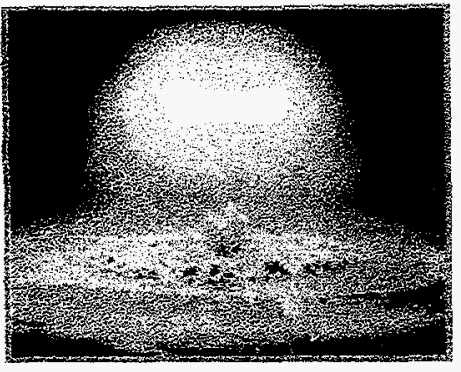

Atmospheric

STOKES PLUMBOB

August 7, 1957

$19 \mathrm{kT}$ at $1500 \mathrm{ft}$ above ground

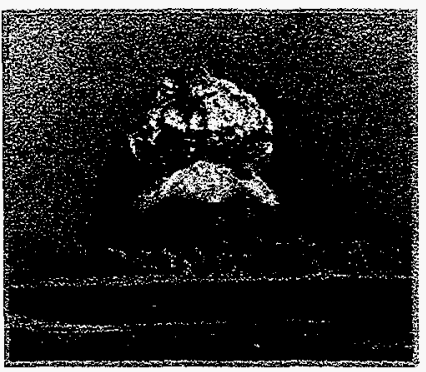

Atmospheric

FIZEAU, Sept. 14, 1957

$11 \mathrm{kT}$ at $500 \mathrm{ft}$

above ground

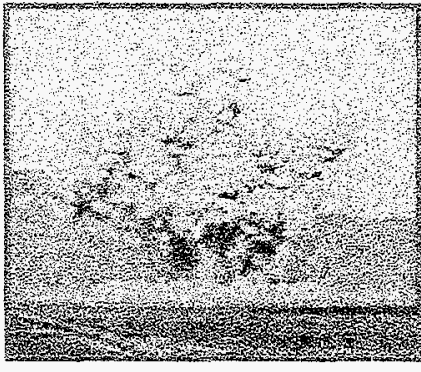

Subsurface Major Vent JANGLE UNCLE Nov. 29, 1951

$1.2 \mathrm{kT}$ at $67 \mathrm{ft}$ depth

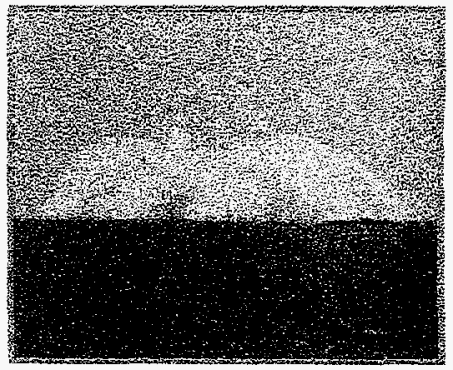

Underwater Gas Vent

WAHOO, May 16, 1958

$9 \mathrm{kT}$ at $500 \mathrm{ft}$ depth

Atmospheric and surface detonations release major quantities of particulate debris to the atmosphere which can readily be observed based on aerosol collections. Subsurface and underwater detonations may only release noble gases of which the radioxenons are by far the most abundant after one day. Confirmation of their occurrence requires detection of the radioxenons. (Photos courtesy of Los Alamos National Laboratory.)

significant fraction of particulate debris to the atmosphere. With further experience by countries conducting underground tests, together with a determined effort by some to minimize or eliminate the release of particulates and radioactive gases, emissions from underground nuclear tests were substantially reduced and in many cases only the gaseous radionuclides were ever released. However, technologies which minimize radioactive gas release, from underground tests for example, maximize the seismic signal and would, therefore, be comparatively easy to detect with proposed seismic monitoring networks. Of the noble gas fission products which are produced, the radioxenons are the most abundant. For example, the approximate amounts of ${ }^{135} \mathrm{Xe}$ $(9.1 \mathrm{hr}),{ }^{133 \mathrm{~m}} \mathrm{Xe}$ (2.19 day), ${ }^{133 \mathrm{~g}} \mathrm{Xe}(5.24$ day), and ${ }^{13 l m} X e$ (11.9 day) which are instantly produced from a 1-kT plutonium fission weapon are $2 \times 10^{16}$, $2 \times 10^{14}, 2 \times 10^{13}, 5 \times 10^{9} \mathrm{~Bq}$, respectively. The quantities of ${ }^{133 \mathrm{~g}} \mathrm{Xe},{ }^{135} \mathrm{Xe}$ and ${ }^{131 \mathrm{~m}} \mathrm{Xe}$ from a detonation increase by about an order of magnitude during the first hour or two following a detonation due to ingrowth from precursor fission products, and if they are formed in a location where they could be released to the atmosphere, they could increase the airborne radioxenons substantially. However, it is far less likely that radioxenons produced by decay of precursors will be vented. The energy of a detonation could cause much of the radioxenon, which is produced directly, to move rapidly to the surface and be released in a matter of minutes. The precursors, however, would behave according to their chemical properties, perhaps being retained in or near the molten earth material leaving a lesser opportunity for escape of their daughter radioxenons. Nevertheless, if only $1 \%$ of the initially produced radioxenons were released to the atmosphere and any contribution from precursors is ignored, this would amount to $2 \times 10^{14}, 2 \times 10^{12}, 2 \times 10^{11}$, and $5 \times 10^{7} \mathrm{~Bq}$, respectively. These quantities are still very large and, with the exception of ${ }^{131 \mathrm{~m}} \mathrm{Xe}$, they could be detected with high probability by a sensitive radioxenon analyzer in an International Monitoring System (IMS).

\section{EMISSIONS, NATURE AND UNIQUENESS OF THE RADIOXENONS}

The four most important radioxenons which enter the atmosphere from nuclear operations are shown in the illustrations along with their half-lives and unique decay properties. With the automatic radioxenon analyzer, it is possible to measure all of these simultaneously. The principal potential sources of each of these radionuclides in the atmosphere are summarized below.

Principal Potential Sources of the Radioxenons

\begin{tabular}{|l|c|c|c|c|}
\hline & ${ }^{131 \pi \mathrm{Xe}}$ & ${ }^{133 m} \mathrm{Xe}$ & ${ }^{133 \mathrm{~g}} \mathrm{Xe}$ & ${ }^{135} \mathrm{Xe}$ \\
\hline $\begin{array}{l}\text { Weapons } \\
\text { testing vent }\end{array}$ & & $\mathrm{X}$ & $\mathrm{X}$ & $\mathrm{X}$ \\
\hline $\begin{array}{l}\text { Reactor } \\
\text { operations }\end{array}$ & & & $\mathrm{X}$ & \\
\hline $\begin{array}{l}\text { Fuel re- } \\
\text { processing }\end{array}$ & $\mathrm{X}$ & & & \\
\hline $\begin{array}{l}\text { Medical } \\
\text { isotopes }\end{array}$ & $\mathrm{X}$ & & $\mathrm{X}$ & \\
\hline
\end{tabular}

The significant sources of ${ }^{131 m} \mathrm{Xe}$ are limited. This radionuclide is present in irradiated nuclear fuel and will enter the atmosphere when released from the fuel during reprocessing. However, if the

Decay Chains and Fission Yields of Xenon Radionuclides For U-235 tission with U-235 tission neutron spectrum
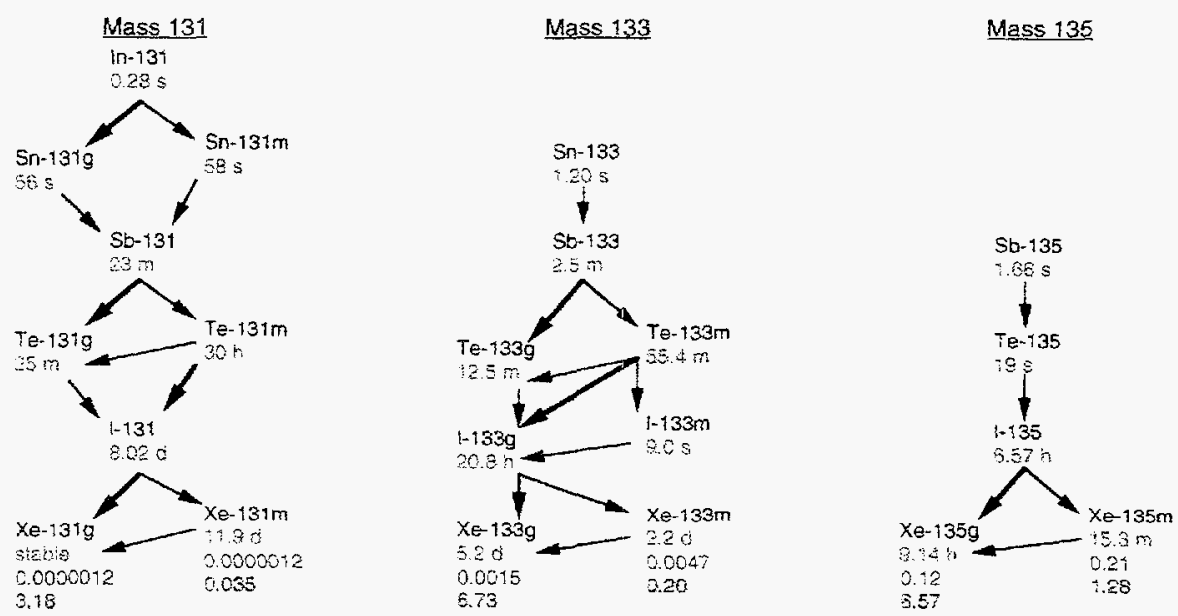

The amounts of the radioxenons which are produced directly in a nuclear detonation (independent fission yield) are small compared with their yields from decay of precursors (cumulative fission yield). However, the independent yields represent the relative amounts of the radioxenons which can be vented immediately after a subsurface nuclear detonation. Half-lives are in green. Heavy arrows represent the dominant decay branch. Yields are in \% of fission. 


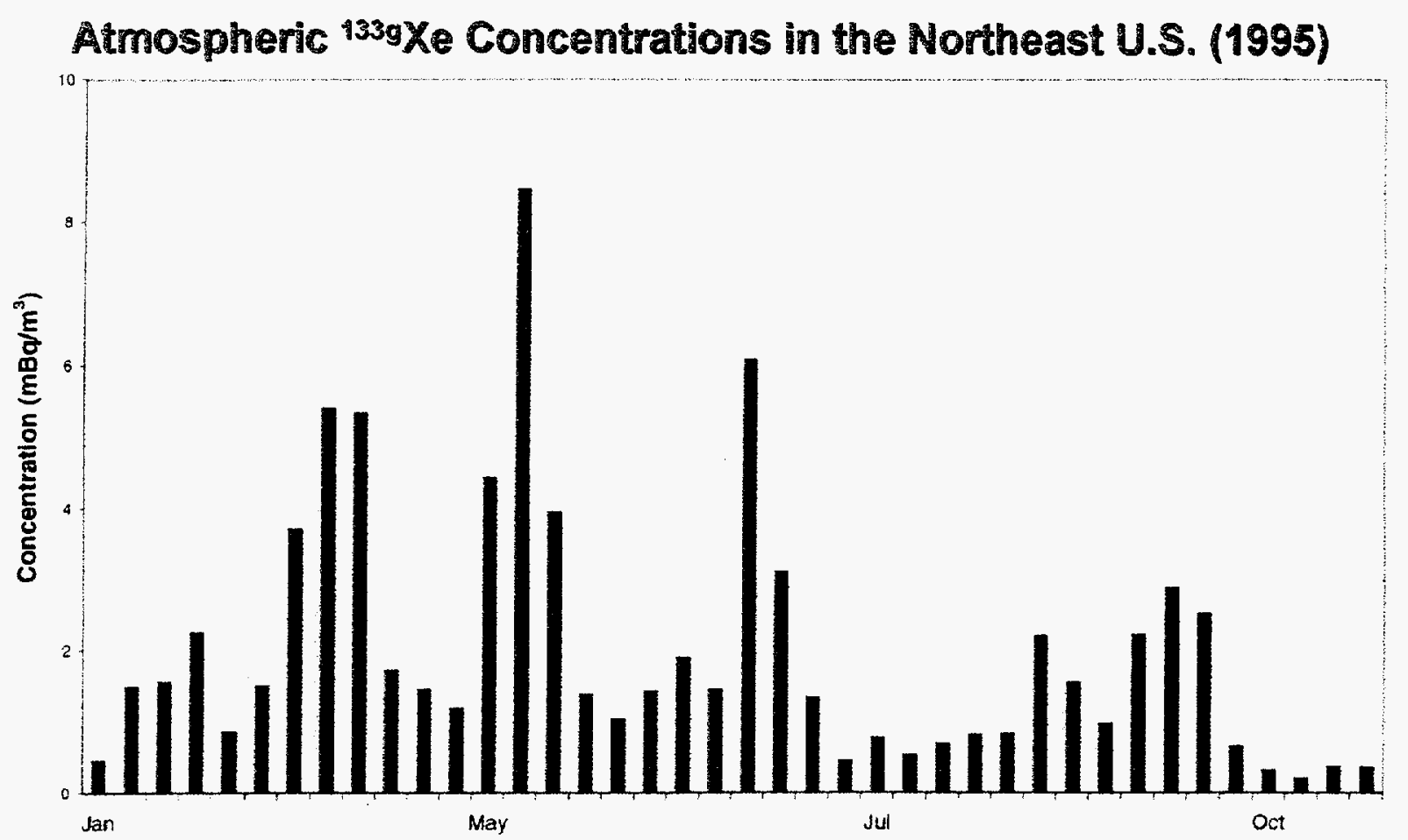

Radioxenons are released in small quantities from all operating nuclear reactors and could pose a serious problem to monitoring for compliance with a Comprehensive Test Ban Treaty (CTBT) if other xenon radionuclides were not measured simultaneousiy. The ${ }^{133} \mathrm{gXe}$ concentrations are easily measurable with a DOE automatic radioxenon analyzer. The ratios of ${ }^{133 m \mathrm{Xe}}$ and ${ }^{135} \mathrm{Xe}$ to ${ }^{1339 \mathrm{Xe} \text {, which }}$ are instantly produced in a nuclear detonation, are 100 and 10,000 times greater, respectively, than those from nuclear reactors, and this allows discrimination between these two sources.

delay time between irradiation and reprocessing is long, 200 days or more, the amounts released are insignificant because of its short half-life. The current practice of storing nuclear fuels for a year or more before reprocessing assures that reprocessing is not a significant source of atmospheric radioxenon. The radionuclide ${ }^{133} \mathrm{Xe}(5.24$ day) is produced for medical diagnostic applications by neutron irradiation of xenon gas and some ${ }^{131 \mathrm{~m}} \mathrm{Xe}$ (11.9 day) is also produced. However, the total quantities of both of these radionuclides which are produced and which may be accidentally released to the atmosphere are small and they should not provide a significant interference in monitoring for nuclear explosion radioxenon in the atmosphere unless a monitoring site were located near a processing or usage site.

Since nuclear fuel reprocessing and medical isotope usage should not result in significant atmospheric releases, there is only one source of airborne radioxenons which may interfere with the monitoring of the radioxenons from nuclear explosions. This source is reactor operations. All of the nuclear power reactors in the world release some radioxenon to the atmosphere, and the quantities currently in the atmosphere are substantial, particularly in the latitudes where most of the world's power reactors are located, i.e., between $30^{\circ} \mathrm{N}$ and $60^{\circ} \mathrm{N}$ latitudes. An example of the 1995 level of the radioxenon ${ }^{133} \mathrm{Xe}$ in the northeast sector of the United States, where some 50 nuclear power reactors are in operation, is shown in the illustration. These concentrations are comparable to or greater than what one might expect at distant monitoring sites from the minor venting of a subsurface detonation, and are therefore of concern. Fortunately, it is possible to distinguish between the spectrum of radioxenons which could be released from a subsurface detonation and those which are released from the operation of a nuclear reactor. For example, the ratio of ${ }^{133 \pi} \mathrm{Xe}$ ( 2.19 day) to ${ }^{133 \mathrm{~g} X e}$ ( 5.24 day) from a subsurface vent would be expected to be more than 100 times greater than from reactor releases, while the ratio of ${ }^{135} \mathrm{Xe}(9.10 \mathrm{hr})$ to ${ }^{133 \mathrm{~g}} \mathrm{Xe}$ would be expected to be about 10,000 times greater.

The illustration on the next page provides a comparison of the ratios of these radioxenons which could enter the atmosphere from venting of a subsurface detonation with those which could be or have been observed in the atmosphere in regions of high reactor density. Because of the very large differences in these ratios, their determination can allow clear differentiation of explosion radioxenons from reactor radioxenons and thus minimize the effect of reactor sources in detecting nuclear explosion material. The simultaneous and sensitive measurement of the radioxenons which provide the basis for calculating these ratios is a key feature of instrument design.

\section{NEED FOR CONTINUOUS MONITORING FOR RADIOXENON}

The intent of a Comprehensive Test Ban Treaty is to prohibit nuclear explosions in any of the earth's environment. An International Monitoring System (IMS) to support such a treaty could provide rapid detection of airbome radionuclides which would confirm evidence from seismic, hydroacoustic, infrasound, or other monitoring systems or provide an entirely independent detection of a nuclear detonation. Since a sensitive monitoring system may always detect some airborne 


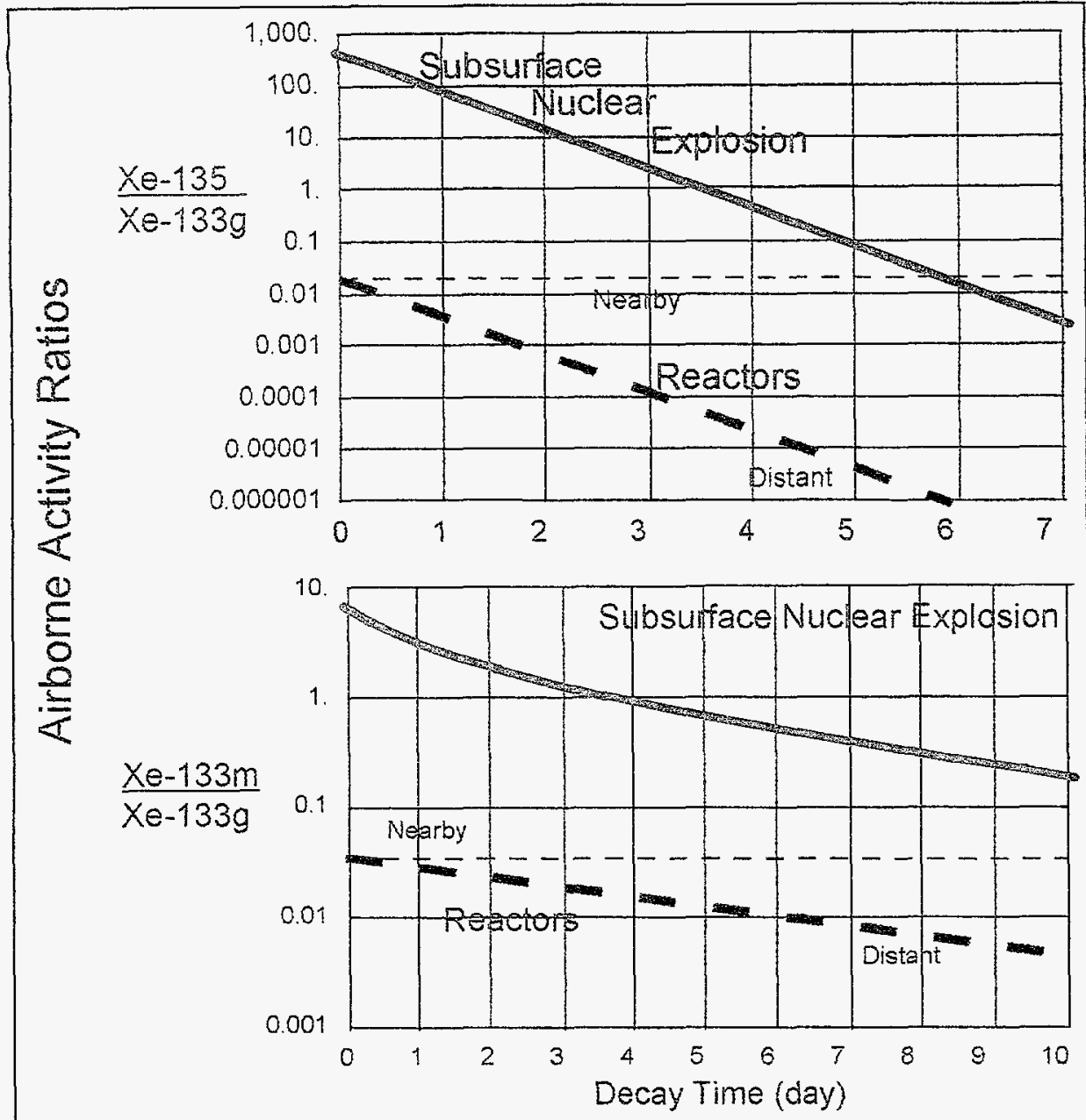

The ratios of the airborne xenon radionuclides which are present in regions of operating nuclear power reactors are dramatically different from those which are instantaneously produced in a nuclear explosion and which could be vented to the atmosphere. These differences are sufficient to distinguish between the sources where sufficient xenon can be collected to permit precise analysis.

radioxenon from reactor operations, it is important to continuously observe these levels and be able to recognize them as a background above which material from a nuclear detonation must be recognizable. If measurements are made continually, then one can be more certain that an elevation in radioxenon concentration is the result of a nuclear detonation and is not simply an increase in the variable background which is maintained by nuclear reactor operations. Even though the radioxenon ratios from a nuclear detonation are very unique, if the concentrations were so low as to seriously limit measurement precision, it would be important to recognize both the differences in the radioxenon ratios and increases in concentration to provide a confident observation of the nuclear detonation.

The importance of continuous radioxenon monitoring is perhaps most evident for scenarios where only minor venting of xenon noble gas radionuclides occurs within minutes following a detonation. In such a case, downwind concentrations at monitoring sites may be barely detectable. There might only be a detectable concentration for a matter of a few hours at a given monitoring site. By carrying out continuous consecutive short-term collections and immediate analyses, made practical through automation, the probability of detecting a small vent will be improved substantially.

\section{NEED FOR HIGH SENSITIVITY MEASUREMENTS}

In monitoring for evidence of an underground detonation where only radioxenons are emitted in significant quantities, the detection probability at downwind monitoring sites will be directly related to detection sensitivity. Detection sensitivity is affected by several factors including the size of the sample which is collected, the counting efficiency, the background counting rate of the instrument, the background concentration of each radioxenon in the atmosphere, the decay time between sample collection and analysis, and the length of the counting period. For example, a 10-fold increase in sample size could provide up to a 10 -fold increase in detection sensitivity. Improving the counting efficiency by 5-fold could provide up to a 5-fold improvement in counting sensitivity. A 1000 -fold reduction in the background counting rate could improve detection by the square root of this number or about 30 -fold. Increasing the counting time by 10 -fold could increase the sensitivity by up to 3-fold, and limiting decay time between collection and analysis from 70 hours to 4 hours could, in the case of the short-lived ${ }^{135} \mathrm{Xe}(9.1 \mathrm{hr})$, improve the detection sensitivity by 100 -fold. All of these parameters were considered in the development of the automatic radioxenon analyzer and were optimized for increased sensitivity where possible.

\section{AUTOMATED NEAR REAL-TIME RADIOXENON MEASUREMENTS}

In order to monitor a Comprehensive Test Ban Treaty based on airborne radionuclide measurements in a practical manner, it would be essential to have automated systems whereby atmospheric levels could be observed continuously. An atmospheric detonation or the major venting of particulate debris from an underground event is comparatively easy to detect with automated particulate sampler/analyzer systems. Where an underground, underwater, or other detonation occurs such that only radioxenon is vented, then detection/verification must be based on xenon separation and 
Separation/Analysis Scheme

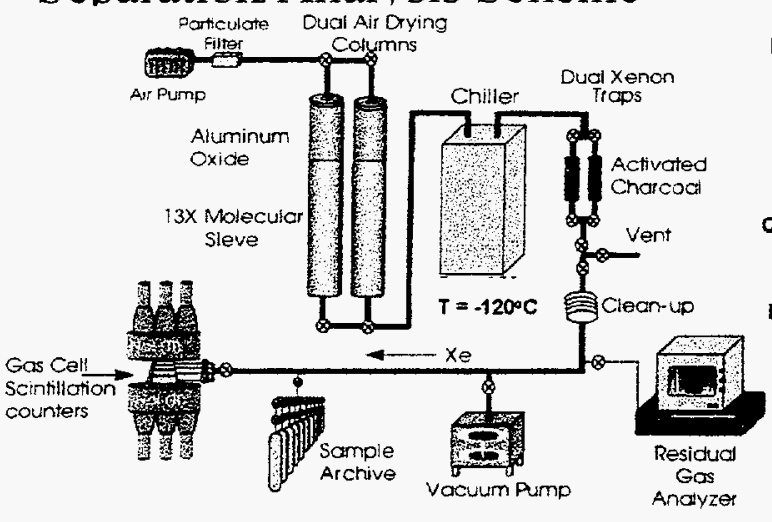

The Xenon Xephyr

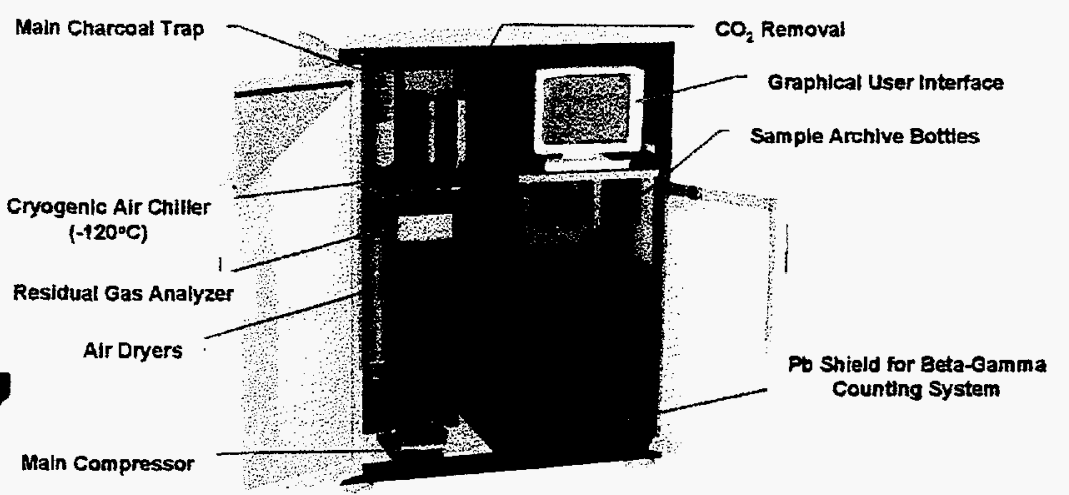

The radioxenon analyzer is a fully automatic unit for ultrasensitive analysis. It provides near-real-time simultaneous measurements of airborne ${ }^{13 l m} X e(11.9 \mathrm{day}),{ }^{133 \mathrm{~m} X e}(2.19 \mathrm{day}),{ }^{133 \mathrm{~g} X e}(5.24 \mathrm{day})$, and ${ }^{135} \mathrm{Xe}(9.10 \mathrm{hr})$. The high-volume (5 to $10 \mathrm{~m}^{3} / \mathrm{hr}$ ) analyzer passes filtered air through a molecular sieve/aluminum oxide bed for removal of moisture, carbon dioxide, acid gases, and part of the radon, and then through a charcoal sorption bed at $-120^{\circ} \mathrm{C}$ for xenon collection. The xenon is then thermally desorbed, purified, and measured by beta (and/or conversion electron)-gamma (or x-ray) coincidence spectrometry. The beta-gamma-ray spectra and radionuclide concentrations are automatically transmitted to appropriate organizations. The gas samples can be retained for central laboratory confirmatory anatysis. By automation and making this technology commercially available, all countries can have the means to monitor radioxenons under a CTBT.

radionuclide composition. Previous methods for measuring atmospheric radioxenon have been expensive, laborious, very time-consuming, and have had limited sensitivity. Basically they involved separation of xenon from the atmosphere by low-temperature adsorption or cryogenic distillation followed by laboratory-based chromatographic purification and counting the radioxenon by one of a number of procedures which were adequate for the intended purpose. The new technology developed at the DOE/PNNL allows near real-time monitoring with an automated analyzer which measures radioxenons on integrated samples collected a few times each day from very large volumes of air and allows automatic transmission of concentrations to the National and International Data Centers. A schematic of the separation and counting systems employed in this automatic radioxenon analyzer is shown in the illustrations.

The separation and purification of atmospheric xenon, which contains the radioxenon isotopes of interest, require special care because of its low concentration, 87 parts-per-billion, and the fact that the ambient activity of the naturally occurring radioactive gas, ${ }^{22} \mathrm{Rn}$, can be hundreds of thousands of times greater than the sensitivity limits that the automated radioxenon analyzer is designed to achieve. Thus, the system (affectionately known as the Xenon Xephyr) must be capable of automatically separating, purifying, and analyzing the radioxenons by procedures which require consistently reproducible separations and very selective counting. The separation and detection procedures involve the following principles.

Air is continuously filtered and the moisture and most of the carbon dioxide and some radon removed at near room temperature on a large molecular sieve/ aluminum oxide column. The air then flows through a chiller where its temperature is lowered to $-120^{\circ} \mathrm{C}$, through a short charcoal bed (radon trap) and on through a longer charcoal bed which is maintained at approximately $-120^{\circ} \mathrm{C}$ and which collects the xenon and a fraction of the other atmospheric gases. The radon trap operating at $-120^{\circ} \mathrm{C}$ is about $50^{\circ} \mathrm{C}$ below its freezing point $\left(-71^{\circ} \mathrm{C}\right)$ and retains better than $99 \%$ of this gas during an operating period. It also retains up to $5 \%$ of the xenon product (freezing point $-112^{\circ} \mathrm{C}$ ); however, all of the remaining xenon is retained on the much larger second trap where the linear flow rate is about onefourth and the bed length 5 times greater. Once the collection interval of 8 to 12 hours is complete, the air stream is diverted to a second charcoal trap system and a second collection process is initiated. The first radon trap is regenerated by backflushing with nitrogen at $300^{\circ} \mathrm{C}$. Meanwhile, the xenon trap is evacuated while the temperature is allowed to rise to $-100^{\circ} \mathrm{C}$ which allows the release of most of the lower boiling constituents, including oxygen and argon. It is then filled with dry nitrogen, and the temperature raised to $300^{\circ} \mathrm{C}$. The xenon is eluted with $300^{\circ} \mathrm{C}$ nitrogen gas flowing at $300 \mathrm{cc} / \mathrm{min}$ for three hours. This eluent is cooled to about $25^{\circ} \mathrm{C}$, flows through a $\mathrm{CO}_{2}$ /moisture trap to remove any traces of $\mathrm{CO}_{2}$ and $\mathrm{H}_{2} \mathrm{O}$, is cooled to $-40^{\circ} \mathrm{C}$ and passes through a short molecular sieve trap to remove any remaining radon, through a cooler to reduce its temperature to $-120^{\circ} \mathrm{C}$, and through a small charcoal bed where the xenon is collected. The small xenon trap $(0.5 \mathrm{cc})$ is then evacuated while the temperature is allowed to rise to about $-100^{\circ} \mathrm{C}$. This facilitates the removal of most of the remaining atmospheric gases. While maintaining the vacuum, the sorption bed is valved to a $10-\mathrm{cc}$ gas cell scintillator counter and the gas analysis port of an on-line residual gas analyzer. This end section of the analysis system is then valved off and the temperature in the small xenon trap raised to $300^{\circ} \mathrm{C}$ for 5 minutes to desorb the trapped xenon and cause most of it to flow into the gas cell scintillator counter. Following the xenon transfer, a valve is closed to retain the radioxenon in the scintillation counting cell where it is measured for a period of up to 36 hours. The residual gas analyzer provides precise analysis of the fraction of xenon in the gas cell, which is about $40 \%$. This information, together with gas pressure and radioxenon counting rates, permits the automatic 


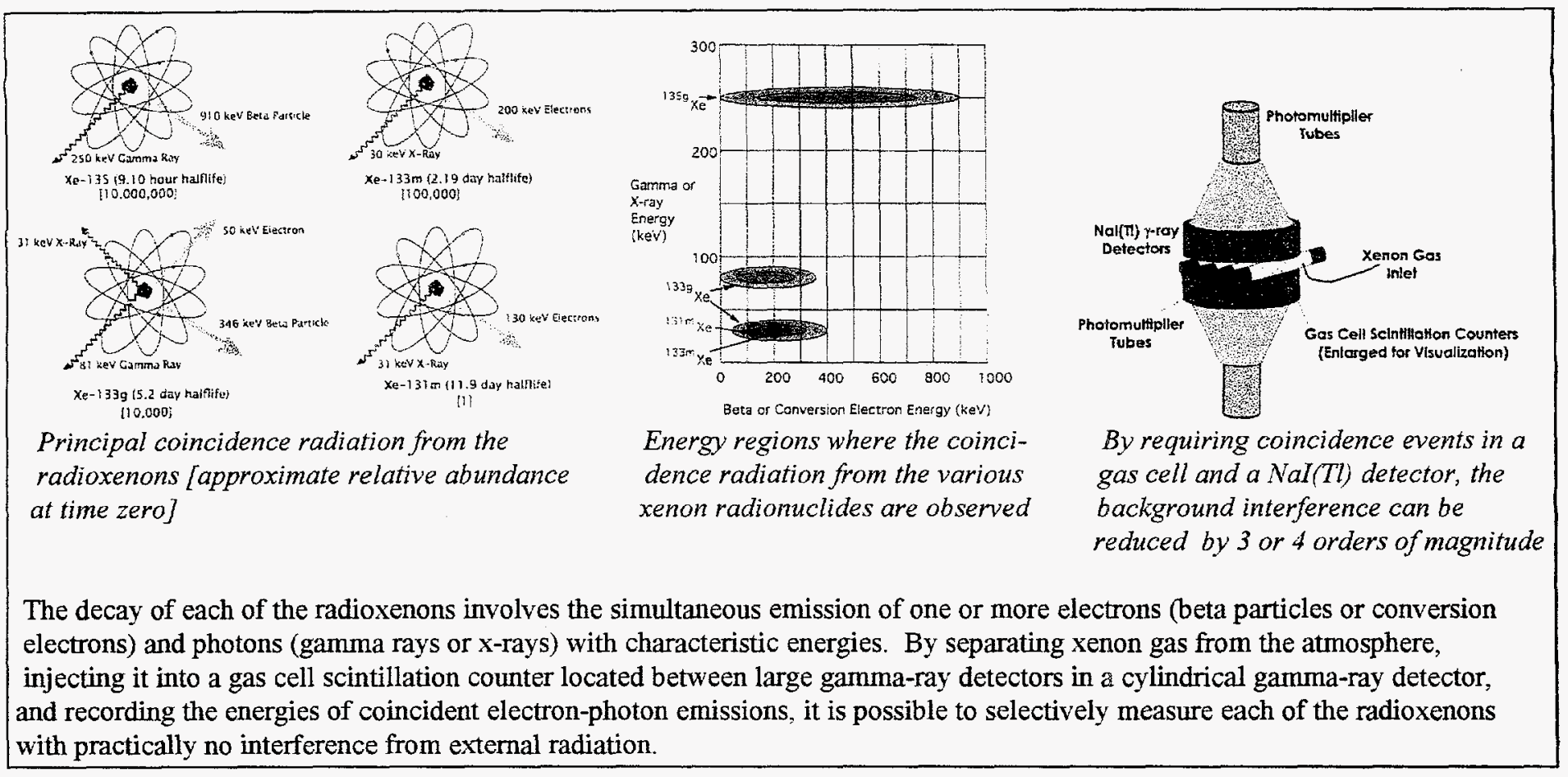

calculation of the individual xenon radionuclide concentrations. Automation allows the whole process of separation and counting to be continued on subsequent samples so that up to four samples are simultaneously being analyzed in separate gas scintillation cells which are viewed by two large area $\mathrm{NaI}(\mathrm{TI})$ detectors of a gammaray spectrometer. The gamma-ray spectral data can be automatically transmitted to the National Data Center at the conclusion of the measurement or at an earlier time if nuclear weapons radioxenons are observed.

\section{ACHIEVING RELIABILITY AND HIGH SENSITIVITY}

The automatic radioxenon analyzer design goal is to operate without consumables and maintenance for periods of a year or more. The nitrogen gas required in the elution process is produced with a small nitrogen generator which is an integral part of the system. All of the processes involved in the separation do require precise control; however, their automation is straightforward and remote reliable operation can be maintained. All of the sorption columns are automatically regenerated in the process except the $\mathrm{CO}_{2}$ trap which removes the last trace of $\mathrm{CO}_{2}$ in the final xenon cleanup. While these are not regeneratable, they have sufficient capacity to allow operation for a year or more.

This approach, which can provide a 100to 1000 -fold better sensitivity than previous methods for a given collection period, results from the collection of a 10- to 25-fold larger sample during an 8- to 12-hour period, 3- to 4-fold higher counting efficiency, a $10^{3}-$ to $10^{4}$-fold lower background, and the almost immediate automatic sample analysis to minimize losses of the short-lived xenons to radioactive decay. Delays of several hours to a few days could result in major losses of ${ }^{135} \mathrm{Xe}(9.10 \mathrm{hr})$, and significant losses of the ${ }^{133 m} \mathrm{Xe}$ (2.19 day).

A key to the very high-sensitivity measurement of the radioxenons is that the gas cell scintillator counters sense electrons emitted in either nuclear beta decay or intemal conversion and measure their energy. These electrons serve as triggers for recording the energies of gamma or x-rays which are emitted at essentially the same time as the electrons. For example, ${ }^{135} \mathrm{Xe}$ $(9.1 \mathrm{hr})$ decays by emission of beta particles (electrons) with possible energies up to $910 \mathrm{keV}$. These electrons are in coincidence with a $250-\mathrm{keV}$ gamma ray as indicated in the illustration. The gas cell scintillator counter observes an electron and triggers the gamma-ray spectrometer to accept a coincident garnma-ray signal from either of the $\mathrm{NaI}(\mathrm{Tl})$ gamma-ray detectors. By using this approach, it is possible to reduce the background counting rate by about four orders of magnitude with only a minor decrease in counting efficiency.

Similarly, the principal decay mode of ${ }^{133} \mathrm{Xe}$ involves the emission of an internal- conversion electron from a 233-keV transition. The detectable radiation consists of a $31-\mathrm{keV} \mathrm{x}$-ray and a $200-\mathrm{keV}$ conversion electron. The $200-\mathrm{keV}$ electron is easily and selectively observed in the gas cell scintillation counter and serves as a trigger to permit storage of the $31-\mathrm{keV} \mathrm{x}$-ray which may be observed by either of the $\mathrm{NaI}(\mathrm{TI})$ detectors. Again, the background interference in the measurement of the ${ }^{133 \pi} \mathrm{Xe}$ is reduced by about four orders of magnitude by requiring a unique signature from the gas cell scintillation counter to trigger storage of the x-ray observed by a $\mathrm{NaI}(\mathrm{Tl})$ crystal.

The third radionuclide of major importance is the ${ }^{133} \mathrm{Xe}$ which decays by emission of a $346-\mathrm{keV}$ (maximum energy) beta particle (electron) in coincidence with an $81-\mathrm{keV}$ gamma ray. By requiring a beta coincidence trigger from the gas cell scintillation counter to trigger storage of the 81-keV gamma-ray signal from the NaI(Tl) crystal, it is again possible to reduce background interference by about four orders of magnitude. In the case of ${ }^{133 \mathrm{~g}} \mathrm{Xe}$, there is also a separate signature resulting from the internal conversion of about $63 \%$ of the $81-\mathrm{keV}$ transition energy to provide a $50-\mathrm{keV}$ internal conversion electron and a $31-\mathrm{keV}$ $\mathrm{x}$-ray. A coincidence event between these two emissions plus the beta particles serves as an additional basis for very selectively measuring the concentration of the ${ }^{133 \mathrm{~g}} \mathrm{Xe}$.

The ${ }^{131 m} \mathrm{Xe}$ (11.9 day) is not produced in significant amounts in a nuclear 
explosion and would not normally be present in a significant quantity in the atmosphere since it is only released in minor amounts in the case of dissolution of nuclear fuel or in medical isotope production/usage. However, it would be readily observable if it were present in significant quantities. Its principal decay mode involves coincidence emission of a $133-\mathrm{keV}$ conversion electron and a $31-\mathrm{keV}$ xenon $x$-ray. The resolution of the gas cell scintillation counter is sufficient to permit rather selective detection of the conversion electron and thereby the characteristic $x$-ray. However, its differentiation from
${ }^{133 m} \mathrm{Xe}$ must be based on the energy of its conversion electron: $133 \mathrm{keV}$ versus $200 \mathrm{keV}$.

\section{INDEPENDENT AND COMPLEMENTARY VERIFICATION}

The continuous measurement of the radioxenons at sites worldwide within an International Monitoring System would make a critically important contribution to verification of a Comprehensive Test Ban Treaty. The extremely high sensitivity and selectivity of the automatic radioxenon analyzer, combined with its instant data transmission feature, ensure early and unambiguous detection of any covert nuclear explosions where significant gas venting occurs. Evasion scenarios which could minimize or essentially eliminate other indicators of a test tend to increase the likelihood of radioxenon release to the atmosphere. Thus, a would-be treaty violator must be willing to take a major risk of detection even if he were able to reduce other signatures including seismic, hydroacoustic, and infrasound, to levels of questionable detectability.

\section{THE AUTHORS}

Richard W. Perkins and Leslie A. Casey combined their interests in the development of enhanced radionuclide detection technologies for treaty verification and proliferation detection. Perkins is currently Chief Scientist Emeritus of the National Security Division at the Pacific Northwest National Laboratory where he has conducted work leading to the publication of hundreds of scientific articles on highly sensitive radionuclide measurements. Casey is Manager of the Department of Energy CTBT Research and Development Program within the Office of Nomproliferation and National Security, and oversees much of the nation's development in advanced radionuclide measurements.

Major contributors to the development of the automatic radioxenon analyzer at the PNNL include: Theodore W. Bowyer, Keith H. Abel, Paul L. Reeder, Robert C. Thompson, Walter K. Hensley, Mark E. Panisko, A. David McKinnon, and Ray A. Warner.

\section{FURTHER READING}

ATMOSPHERIC RADIONUCLIDE MONITORNG-A SWEDISH PERSPECTTVE. L. E. DeGeer. Monitoring a Comprehensive Test Ban Treaty, NATO ASI Series E: Applied Sciences-Vol. 303:157-177 (1996). Kluwer Academics, Dordrecht, The Netherlands.

XENON-133: AMBIENT AIR CONCENTRATION IN UPSTATE NEW YORK. C. O. Kunz, Atmospheric Environment 23(8):1827-1833 (1989).

THE RADIOCHEMISTRY OF THE RARE GASES. F. F.Momyer, Jr., Nuclear Sciences Series, National Academy of Sciences, National Research Council, October 1960.

CTBT R\&D HOME PAGE, WORLDWIDE WEB. (http:/www.ctbt.md.doe.gov).

\title{
DISCLAIMER
}

\begin{abstract}
This report was prepared as an account of work sponsored by an agency of the United States Government. Neither the United States Government nor any agency thereof, nor any of their employees, makes any warranty, express or implied, or assumes any legal liability or responsibility for the accuracy, completeness, or usefulness of any information, apparatus, product, or process disclosed, or represents that its use would not infringe privately owned rights. Reference herein to any specific commercial product, process, or service by trade name, trademark, manufacturer, or otherwise does not necessarily constitute or imply its endorsement, recommendation, or favoring by the United States Government or any agency thereof. The views and opinions of authors expressed herein do not necessarily state or reflect those of the United States Government or any agency thereof.
\end{abstract}


I

I

I

I

I

I

I

I

I

I

|

I

I

I

I

I

I

,

I 